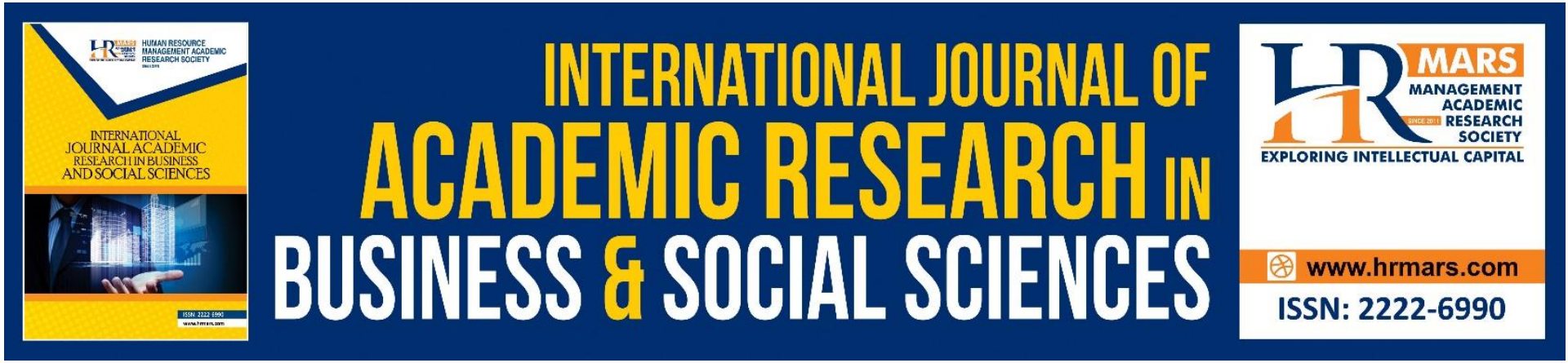

\title{
A Case Study of a Mainstream School Child with Depressive Symptoms, Academic Difficulties and Low Self-esteem Problems treated using Cognitive Behavior Techniques as a Therapy
}

Kiran Akbar Khan, Ayesha Ashiq, Saadia Dildar

To Link this Article: http://dx.doi.org/10.6007/IJARBSS/v11-i2/8886 ～DOI:10.6007/IJARBSS/v11-i2/8886

Received: 20 December 2020, Revised: 16 January 2021, Accepted: 30 January 2021

Published Online: 21 February 2021

In-Text Citation: (Khan et al., 2021)

To Cite this Article: Khan, K. A., Ashiq, A., \& Dildar, S. (2021). A Case Study of a Mainstream School Child with Depressive Symptoms, Academic Difficulties and Low Self-esteem Problems treated using Cognitive Behavior Techniques as a Therapy. International Journal of Academic Research in Business and Social Science, 11(2), 558-571.

Copyright: @ 2021 The Author(s)

Published by Human Resource Management Academic Research Society (www.hrmars.com)

This article is published under the Creative Commons Attribution (CC BY 4.0) license. Anyone may reproduce, distribute, translate and create derivative works of this article (for both commercial and non-commercial purposes), subject to full attribution to the original publication and authors. The full terms of this license may be seen at: http://creativecommons.org/licences/by/4.0/legalcode

Vol. 11, No. 2, 2021, Pg. 558 - 571

Full Terms \& Conditions of access and use can be found at http://hrmars.com/index.php/pages/detail/publication-ethics 


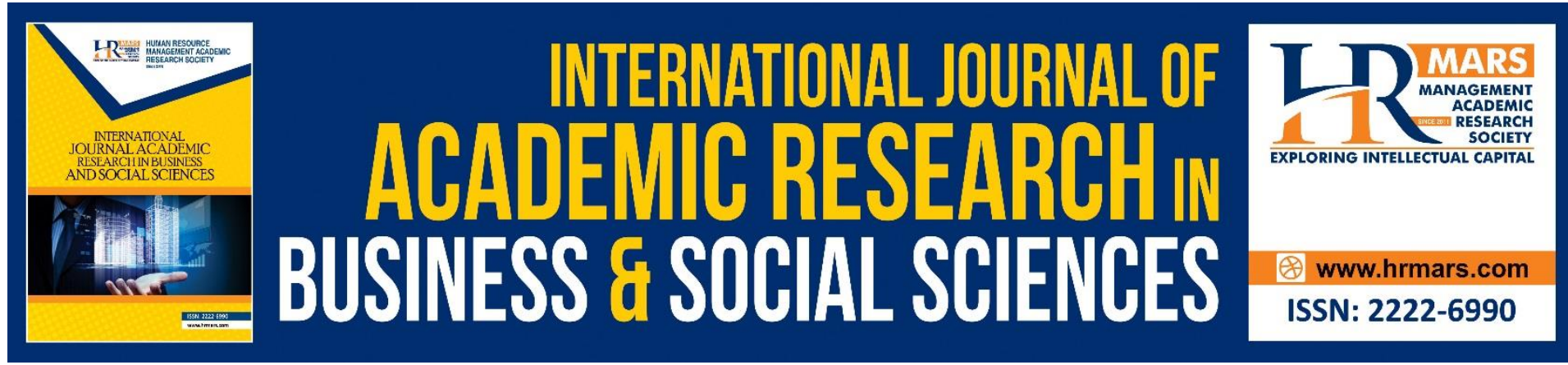

\title{
A Case Study of a Mainstream School Child with Depressive Symptoms, Academic Difficulties and Low Self-esteem Problems treated using Cognitive Behavior Techniques as a Therapy
}

\author{
Kiran Akbar Khan, Ayesha Ashiq, Saadia Dildar \\ GC University, Lahore Clinical Psychology Unit
}

\begin{abstract}
Aim of the Study: The basic aim of the present case study is to demonstrate the significance of Cognitive Behavior Techniques used as a therapy for the reduction and improvement in Depressive Symptoms, Academic Difficulties and Low Self-esteem Problems in a mainstream school child.
\end{abstract}

Place of Study: Lahore, Pakistan

Research Design: Case Study

Sample: This paper is based on a case of a 13 years old girl of grade $8^{\text {th }}$ with Depressive Symptoms, Academic Difficulties and Low Self-esteem Problems.

Method: Psychological Assessment of the client was done with the help of Behavioral Observation, Semi-Structured Interview, Subjective Ratings of the presenting problems, Demographic Data Sheet, Portfolio Assessment, Paired Associate Learning Test (PALT) (Mahmood \& Sheikh, 1989)., Children Depression Inventory (CDI) (Kovacs, 1979) and Selfesteem Scale for Children (Saleem \& Mahmood, 2010). Counseling plan was devised for the client included Rapport Buildup, Psycho-education, Supportive Therapy, Deep Breathing, Activity Scheduling, Dictionary concept, Chunking Method and Happy Pyramid. Self-esteem building exercises, Study Skills, Assertiveness Training and Social Skills Training were used for proposed management of the client's problems. Total 8 sessions were conducted with the client.

Results: The overall results of all psychological assessment tools showed that the academic performance of the client was below average, very highly severe depressive symptoms and low self-esteem problem as well as the overall outcomes of the counseling and management plan revealed that decrease in the intensity of the depressive symptoms and improvement in academic difficulties and problems related to the low self-esteem in the client.

Conclusion: on the basis of case study results, it has been concluded that the proper use of the Cognitive Behavior Techniques as therapy provided more effective results for the reduction and improvement in Depressive Symptoms, Academic Difficulties and Low Selfesteem Problems in a mainstream school child. Recommendation and Implications were also discussed. 
Keywords: Depressive Symptoms, Academic Difficulties, Low Self-Esteem And Cognitive Behavior

\section{Introduction}

The modern developments in the problems related to psychology field have increasing a ratio in the initial testimony of depressive symptoms in the school kids' community (Alesi, Rappo \& Pepi, 2014). Depression is a familiar and most serious mood disorder that is present in both children and adults. For the diagnoses of depression, DSM-5 outlines the following criteria five or more symptoms have been present during the same 2-week period and represent a change from previous functioning; at least one of the symptoms is either (1) depressed mood or (2) loss of interest or pleasure. Other symptoms are as significant weight loss or gain, psychomotor agitation or retardation, fatigue or loss of energy, diminished ability to think or concentrate and recurrent thoughts of death, recurrent suicidal ideation without a specific plan. According to DSM-5, the symptoms cause clinically significant distress or impairment in social, occupational, or other important areas of functioning. The episode is not attributable to the physiological effects of a substance or to another medical condition. (American Psychiatric Association, 2013).

Academic Performance of student is a significant element and as an important central point from which whole education system that is used to be revolves. (Rono, \& Reuben, 2015). Annie, Howard and Midred (1996) argued that one of the major aims of schools is academic performance and achievement of pupils. Academic Performance ascribe that what skills and knowledge a student has learned by his / her academics and is assess by using standardized assessment tools ( Academic Performance Scales, Portfolio Assessments) (Santrock, 2006). According to Narad and Abdullah (2016), Academic Performance is a learning outcome that is measured by the grades of the students, he / she gets by his / her teacher remarks and other learning objectives arranged by students and teachers to be get done by a limited duration of time. Hoyle (1986) explained educational institute specially schools are formed for the main purpose to reveal the education, aptitude, academic learning and knowledge of students for improving their academic performance

Self-esteem is a central construct in the different fields related to psychology as clinical, social, development and in personality domain and its significance has been studied for nearly a century in the mental health issues (Greenier, Kernis and Waschull, 1995). Selfesteem plays an important role for physical and mental health of school-aged children's because balanced stage of self-esteem related to the child's school academic performance, physical and mental well-being as well as generative behavior (Pelish, 2006). One of the pioneers in this domain is Rosenberg (1965) and he defined the self-esteem indicate as an person's thoroughly positive appraisal about himself / herself and a person felt himself / herself as a worthy and respectful with high self-esteem and vice versa. Moreover, Sedikides and Gress (2003) defined self-esteem as individual's judgment or personal option about one's own self respect, self worth, positive or negative point views about self. Furthermore, selfesteem is considered as an important contributor for student's academic success in their education life especially in school life. (Ferkany, 2008; Humphrey, 2004).

Cognitive Behavior Therapy is a scientific, structured, problem targeted approach which indicates the great beneficial and efficiency for mental disorders (depression, schizophrenia, anxiety disorders, obsessive, compulsion disorder, substance abuse etc) as well as for those (children, adolescents, adults) who have minor mental health issues like 
depressive symptoms without fulfill any depression criteria, low self esteem problem, academic difficulties, adjustment issues etc (Adam \& Dudas, 2013).

So, on the whole, it has been revealed that student's below average academic performance is more associated with depressive symptoms and low global self-esteem than higher achievers. So, in the present case study, cognitive behavioral techniques as a therapy has been found very effective in treating the depressive symptoms, poor academic performance and low self-esteem problems in the client. A case study is presented here.

\section{Case Report}

The client A.G., 13 years old girl was the student of $8^{\text {th }}$ grade and $1^{\text {rd }}$ born among three siblings. She was referred by her teacher to the trainee school counselor for the purpose of psychological assessment and management with the presenting problems as incorrect English spelling writing problem in English medium subjects (i.e. English, General Science and Computer Science), difficulty in memorizing long questions of Computer Science, lack of interest in studies, faced difficulty in speaking correct English words and also with some depressive symptoms (i.e. depressed and sad mood, lack of interest in daily activities, she liked to stay at home alone and also she showed less social and friendly attitude with her friends and other class fellows), that all things may lead to low self-esteem issues in the client.

As reported by the client that her problem of incorrect English spelling writing problem started one and half years back, when she was in $7^{\text {th }}$ grade. But that problem less severe in $7^{\text {th }}$ grade and became severe in $8^{\text {th }}$ grade, when she was shifted from Urdu to English medium and she wanted to study General Science and Computer Science in Urdu medium, but she faced more difficulties in learning General Science and Computer Science subjects in Urdu medium due to difficult terminologies that used in Urdu medium then she had taken a decision to study these subjects in English medium.

Currently, the client in $8^{\text {th }}$ grade and she also faced more difficulty in comprehension and pronunciation of difficult words in English, General Science and Computer Science subjects. She lacked the basic study skills like dictionary use etc. necessary for acquiring knowledge. Due to her major problem, she was unable to write correct words and she got poor grades in her class test and in school terms that may lead to low academic self-esteem, lack of interest in studies in the client and became anxious about her future progress.

The client also reported that she faced some problems in memorizing long questions of Computer Science. She did not know how to memorize and learn more difficult lessons of Computer Science. Due to her problem, her self-esteem became very low, because she did not perform well in long questions of Computer Science.

The client wanted to go academy for her good academic progress and for her good preparation of final board exams, but the mother of the client showed strict attitude towards her for this regard and she did not give permission to the client for academy because, her mother wanted to stay at home after school time. Due to her mother's strict attitude, the client also experienced some type of depressive symptoms like depressed and sad mood, loss of interest in daily activities, she liked to stay at home alone and she also showed less social and friendly attitude with her friends and other class fellows.

From background information, it has been revealed that she belonged to a middle socio-economic status. She lived in a nuclear family system. There are five members in her family. According to the client, her father is 42 years old and his education till Metric. Her father was driver of Deputy Speaker Officer in Punjab Assembly. He had a loving attitude towards all his children. But her father was too much busy in his duty and came at home on 
weekend. And he spends less time with the client and her brothers. But client reported satisfactory relationship with his father. Her mother was 38 years old, housewife and her education till grade $8^{\text {th }}$. The client's relation with her mother was not satisfactory because her mother showed strict attitude towards the client and she did not give permission to the client to go anywhere expect school. Due to her mother strict attitude, she had weak bonding with her mother and she reported unsatisfactory relationship with her mother. The client had two siblings i.e. two brothers. The client was elder among them. Her $1^{\text {st }}$ brother was 9 years old and studying in $4^{\text {th }}$ grade. The client reported that he was very polite and kind by nature and she had satisfactory relationship with him. Her $2^{\text {nd }}$ youngest brother was 6 years old and studying in $1^{\text {st }}$ grade. The client was very attached with him and she had satisfactory relationship with him. According to the client, general home atmosphere under which she lives was satisfactory but sometime became stressful when her mother showed strict attitude towards herself.

During history taking, the behavioral observation (Furr \& Funder, 2007) of the client was assessing, as client was 13 years old girl who seemed to be of her stated age. She seemed much tensed and anxious and she was not maintaining the proper eye contact. Her tone of voice was a bit low. She had a normal height and weight. She was dressed properly in neat and clean uniform. Her hair was properly combed. During the initial sessions, it was observed that the client was quite uncomfortable and she seemed to be a bit anxious, when asked she reported that she felt quite nervous and was feeling shy in front of the trainee school counselor. But gradually she felt much comfortable in the forward sessions. Whenever asked from the client, she answered appropriately to each question. As maze activity was used with the client for rapport buildup and she liked that activity and felt more comfortable with the trainee school counselor at the end of the session.

For collecting baseline data, Behavioral Observation (Furr \& Funder, 2007), SemiStructured Interview (Davison \& Neale, 2001) with the teacher and client, Subjective Ratings of the presenting problems (Spiegier, 1998), Demographic Data Sheet, Portfolio Assessment (Divvit \& Carey, 2007), Paired Associate Learning Test (PALT) (Mahmood \& Sheikh, 1989)., Children Depression Inventory (CDI) (Maria Kovacs, 1979) and Self-esteem Scale for Children (Saleem \& Mahmood, 2010) as well as intervention plan was done with the client.

\section{Method}

\section{Participants}

Current research narrates the case study of a child. The study was conducted at Lady Maclagon Girls High School (LMGHS). The demographics and other information are given in the introduction section.

\section{Provisional Hypotheses}

- On the basis of her initial information gathered, it has been hypothesized that client might have some depressive symptoms due to mother's strict attitude towards the client.

- It was hypothesized on the basis of initial information; the client had academic difficulties which revealed that the client might have inappropriate learning strategies as well as lack of phonological awareness of similar words in English which might be because of improper guidance.

- It was also hypothesized that client might have self-esteem issues because of her English spelling writing problem. 


\section{Materials and Measures}

\section{Demographic Bio Data Sheet}

A demographic bio data sheet was used with the client for collecting information regarding her bio data as name, age, gender, class, no. of siblings, birth order, Institute, family structure, socio-economic status, informant and no. of sessions.

Portfolio Assessment (Divvit \& Carey, 2007)

Academic Assessment. Academic assessment was done with client in order to through assess the level of her academic problems. For this purpose, reading and written assessment was done.

Oral Assessment. The client's reading assessment was done by asking her to read a paragraph from English and computer books. The rationale of it was to verify out how much she had faced difficulty in reading and pronounce the words of English.

Quantitative Interpretation.

Table 3

The Results of Reading Task of English and Computer Science Subjects by the Client

\begin{tabular}{llll}
\hline Subjects & Total Words & Correct Words & Mistakes \\
\hline English & 40 & 12 & 28 \\
Computer Science & 35 & 10 & 25 \\
\hline
\end{tabular}

Qualitative Interpretation. It was assessed that she was unable to read difficult word from English and Computer Science books and she had learned the wrong words through role learning method without considering the appropriateness of the word pronunciation.

Written Assessment. To assess the severity of her problems in English and Computer Science subjects, the paragraph was picked up from her text book. Her writing assessment was also done by asking to write different words from English and Computer Science Books.

Quantitative Interpretation.

Table 4

The Results of Dictation of English and Computer Science Subjects by the Client

\begin{tabular}{llll}
\hline Subjects & Total Words & Correct Words & Mistakes \\
\hline English & 20 & 8 & 12 \\
Computer Science & 15 & 7 & 8 \\
\hline
\end{tabular}

Qualitative interpretation. Written sample was taken to check about her writing skills and she was unable to write it properly as there were many mistakes of difficult words.

Paired Associate Learning Test (PALT) (Mahmood \& Sheikh, 1989). The paired Associate Learning Test was conducted on the client for knowing the learning ability of the client. Quantitative Interpretation. 
Table 5

The Test Trials, Obtained Scores, Mean and the Category of the Client on the Paired Associate Learning Test

\begin{tabular}{llll}
\hline Test Trials & Obtained score & Mean & Category \\
\hline Trial 1 & & & \\
- Easy & 4 & 4.68 & Below Average \\
- Difficult & 2 & 1.48 & Above Average
\end{tabular}

Trial 2

$\begin{array}{llll}\text { - Easy } & 5 & 5.49 & \text { Below Average } \\ \text { - Difficult } & 3 & 2.58 & \text { Above Average }\end{array}$

Trial 3

$\begin{array}{lllc}\text { - Easy } & 6 & 5.73 & \text { Above Average } \\ \text { - Difficult } & 3 & 3.03 & \text { Average }\end{array}$

Qualitative Interpretation. The paired Associate Learning Test (PALT) was administered on the client. Client took almost 7 minutes to complete the test. During the administration of test, the client was very attentive and fully concentrates on the instructions given by trainee school counselor. The main rationale behind the administration of the test was to assess the child's learning ability as she reported that she faced problems in learning long questions of Computer Science. Three trials of the test were administered. The score of the client on the first trial were below average on the easy words while above average on the difficult words. The same results were obtained from the second trial means below average on the easy words and above average on the difficult words. While in the third trial, it was above average on the easy words and average on the difficult words. The overall client's score on Paired Associate Learning Test indicated that her learning ability was normal and she had the ability to learn and memorize the difficult words of English and long questions of Computer Science. But just she needed proper guidance and attention of which she had been deprived. Moreover, the client had improved her memorizing power on the last $3^{\text {rd }}$ trial, so, it was indicated that she had improved her learning ability in memorizing long questions of Computer Science through practice. From client's history, it was revealed that she faced a lot of problem in memorizing long questions of Computer Science so it would be revealed that she was not repeating answers and her way of learning was not appropriate.

Children's Depression Inventory (CDI) (Kovacs, 1979). The children's depression inventory (CDI) is a psychological assessment tool that measured the severity of depressive symptoms and dysthymic disorder in children and adults (7-17 years old). It contains the 27 depressive symptoms oriented items that are categorized in five major factor scales i.e. Negative Mood, Interpersonal Problems, Ineffectiveness, Anhedonia and Negative self-esteem. 
Quantitative Interpretation.

Table 6

The Factor scales, obtained Scores, T-Scores, T-Sores Range and Category on the Children's Depression Inventory (CDI).

\begin{tabular}{|c|c|c|c|c|}
\hline Factor Scales & Obtained Scores & T-Scores & T- Scores Range & Category \\
\hline Negative Mood & 8 & 81 & Above 70 & $\begin{array}{l}\text { Very Much } \\
\text { Above Average }\end{array}$ \\
\hline Interpersonal Problems & 2 & 64 & $61-65$ & $\begin{array}{l}\text { Above } \\
\text { Average }\end{array}$ \\
\hline Ineffectiveness & 4 & 66 & $66-70$ & $\begin{array}{l}\text { Much Above } \\
\text { Average }\end{array}$ \\
\hline Anhedonia & 9 & 71 & Above 70 & $\begin{array}{c}\text { Very Much } \\
\text { Above Average }\end{array}$ \\
\hline Negative Self-Esteem & 3 & 58 & $56-60$ & $\begin{array}{c}\text { Slightly Above } \\
\text { Average }\end{array}$ \\
\hline Total & 6 & 76 & Above 70 & $\begin{array}{c}\text { Very Much } \\
\text { Above Average }\end{array}$ \\
\hline
\end{tabular}

Qualitative Interpretation. The Children Depression Inventory (CDI) was administered on the client to assess her depressive symptoms. The client took almost 15 minutes to complete the test. During the administration of test, the client was very attentive and fully concentrates on the instructions given by trainee school counselor. The main rationale behind the administration of the test was to check out the severity of symptoms related to depression as she reported some depressive symptoms. The client's overall score on CDI was very much above average. The client's score on factors scales i.e. Negative Mood (very much above average), Interpersonal Problems (Above Average), Ineffectiveness (Much above Average), Anhedonia (very much above average) and Negative Self-Esteem (slightly above average). From client's history, it was revealed that she had depressed and sad mood, lack of interest in daily activities, she liked to stay at home alone and also she showed less social and friendly attitude with her friends and other class fellows.

Self-esteem Scale for Children (SECS) (Saleem \& Mahmood, 2010). The self-esteem Scale for Children was administered to assess the self-esteem issues of the client.

Quantitative Interpretation.

Table 7

The Scales, Obtained Scores, Percentiles and the Category of the Client on the Self-esteem Scale

\begin{tabular}{llll}
\hline Scales & Obtained Scores & Percentiles & Category \\
\hline Academic Self-esteem & 21 & 20 & Below Average \\
Self-Confidence & 28 & 7 & Below Average \\
Social Self-esteem & 20 & 10 & Below Average \\
Low self-esteem & 17 & 90 & Above Average \\
\hline 3F total & 69 & 10 & Below Average \\
\hline
\end{tabular}


Qualitative Interpretation. The Self-esteem Scale for Children (SESC) was administered on the client in order to assess the Academic Self-esteem, Self-Confidence along with the Social Self-esteem and Self-esteem of the client. She took almost 20 minutes to complete the test because initially she got confused between the different items of the test. The overall self-esteem of the client was below average. She scored lower on the Academic Self-esteem, Self-Confidence and Social Self-esteem which meant that the client's sense of worth in academics was very low and her confidence in her abilities was inadequate and also low social self-esteem could be easily related to her shyness and mother's strict attitude towards her. The fourth subscale i.e. self-esteem subscale; the scores indicated that the client's selfesteem was very low. The results of the subscales correlate with the history of the client that the client's academic self-esteem was very low because of her English Spelling problem and most of the time, she remained lonely from others because mother's strict behavior towards her. Due to her problem her self-confidence and self-esteem was very low.

The overall results of measures showed that the academic performance of the client was below average, very highly severe depressive symptoms and Low self-esteem problem.

\section{Pre-intervention Plan}

Before start the proper intervention plan, the trainee school counselor provided brief description about different interventions / techniques with rationale of each technique that used in the intervention plan with the client.

\section{Intervention Plan}

The intervention plan of the client was done by using eclectic approach in therapy. Rapport Building (Blatner, 1994) was done by the trainee school counselor for the purpose to develop trusty relationship between the client and the counselor. As the client like maze drawing, rapport was tried to establish through maze activity and the client liked that activity and was more comfortable with the counselor at the end of the session. Supportive Therapy (Miltenberger, 1997) was done with the client with the main rationale by showing empathy and unconditional positive regard and active listening towards the client and her problems. Confidentiality of the client' information was also done by using supportive psychotherapy. Psycho-education (Davison \& Neale, 2008) was done with the main purpose (rationale) to provide the insight to the client about the nature of her academic and other emotional and behavioral problems and how to deal effectively with it. The client was guided about Deep Breathing (Edwards, 2005). The main rationale of the deep breathing was to relax, overcome the muscular tension and the client's depressive symptoms. Activity Scheduling (Lewinsohn, 1969 ) is a part of Cognitive Behavior Therapy (CBT) in which time management week schedule with days is used with the client that help the clients to enjoy those activities they avoid due to depression, anxiety and other mental health issues. Chunking Method (Miller, 1956) was used with the client with the main rationale in order to help her learn the spellings and pronunciation of difficult words. Dictionary Concept (Jeremy, 2012) was used with the main rationale was to facilitate and enhance the client's vocabulary and also further help her to find out the meaning of difficult words. Happy Pyramid (Agbebire, 2012) is a technique that facilitates the client in learning long questions and client was asked to choose a question which she found difficult to learn. The trainee school counselor asked the client to divide the long question into three passages. When the client divided it the trainee school counselor told her to learn first passage thoroughly, learn the meanings of the passage and try to understand the passage. 


\section{Proposed intervention Plan}

- Different Self-esteem building exercises can be used with the client to improve her self-esteem regarding to her overweight gain and also increased her academic selfesteem related to her academic performance.

- Different Study Skills can be used with the client in order to improve her study habits, conceptual clarity about her subjects.

- Social Skills Training can be used with the client to learn how to improve her social skills.

- Assertiveness Skills Training can be used to help the client how to stand up for your rights but do not violate the rights of others.

The overall outcomes of counseling and intervention plan revealed that she became able to learn about her conceptual clarity related to her studies. She also became more active, take an interest in studies and she felt less depressed. These outcomes showed better effectiveness of cognitive behavior techniques as a therapy to treatment.

Total 8 sessions ( 2 sessions per week with 45 minutes duration for each session) were conducted with the client for the purpose of psychological assessment and management.

\section{Discussion}

Results of the current case study are persistent with the past researches which implied Cognitive Behavior Therapy (CBT) as an active, practical and beneficial approach (intervention) for problems related to depression, lower academic performance and low selfesteem issues. Arnberg and Öst (2014) presented meta-analysis investigation on the effectiveness of Cognitive Behavior Therapy (CBT) in children (8-12 years old) with regard to depressive symptoms. The results indicated that CBT is more effective therapy for the treatment of depressive symptoms in children. Another experimental study proposed that Cognitive Behavior Therapy (CBT) acts as a more efficient treatment for improving academic performance of middle school students. In this study, Comprehensive School Counseling Program that contains the individual, small group counseling and guidance related to classroom lessons as well as to encourage the school counselor how to imply the CBT interventions for improving student's thought process that have positive impact on their academic performance (Zyromski \& Joseph, 2008). Syeda Mohamed Mohamed (2017) investigated the competency of Cognitive Behavior Treatment Program for the improvement in academic anxiety and low academic self-esteem problems in secondary school pupils. Results of this research demonstrated that Cognitive Behavior Treatment Program act as a more powerful tool for the minimization in student's academic anxiety as well as low academic self-esteem and increasing student's academic achievement.

It was revealed from the client's personal history that lack of conceptual clarity skills, Poor performance academics. According to client, poor performance in academics that resulted different problems such as problems regarding the phonological awareness of English language lead to the emergence of other problems i.e. pronunciation of words, Incorrect English spelling writing and conceptual clarity of Computer Science. The reason might be that the client had not strong basis knowledge about English language. The client's regression in her academic life might be attributed to the fact that she was unable to cope with the difficulty level in academics. The client had a limited vocabulary of English language, might be due to which she was unable to understand, comprehend and write efficiently those subjects which were taught in English language. 
From the Client's history of personal factors, it was also revealed that client also had low Academic Self-esteem and general Self-esteem problems. Many researches indicated that those children with high self-esteem are presented themselves as more confident and have good coping strategies to deal with their problems as compared to children who had low selfesteem issues and there is a greater decline in their academics because they are less involved in their class work activities (Laveena, Meena \& Nelson, 2008). In another study, it is also demonstrated that there was a positive relationship between student's academic achievement and self-esteem in which revealed that competence and susceptibility with academic achievement had a greater impact on student' overall self-esteem. (Doodman, Zadeh \& Changizi, 2017).

Due to her problems, the client was also experienced some depressive symptoms that had not good impact on his academic studies. In one research, Hdid and Maliqi (2015) demonstrated that low success in academic performance had the greater chances to the appearance of depressive symptoms in school going children. In another research, Verboom, Sijtsem, Verhulst, Brenda and Penninx (2003) suggested that there was a bi-directional relationship between depressive problems, lower academic performance and poor social well-being in school children and most common in girls as compared to the boys.

The family factors related to client's history revealed that client's mother's strict attitude towards her and lack of educational guidance. She did not give permission to the client for academy because, her mother wanted to stay at home after school time. Due to her mother's strict attitude, the client also experienced some type of depressed symptoms such as she liked to stay at home alone, depressed and sad mood, lack of interest in daily activities. Many researchers have showed that a clear link between parent positive attitude towards their school going children and the children academic success (Grolnick, Friendly \& Bellas, 2009). Moreover, in another study, it has been explained that parent involvement in their children's academics enhanced student's academic motivation, positive attitude and competency towards academic performance (Gottfried \& Fleming, 1994).

The school factors included that the client faced a lot of difficulty in memorizing long questions of Computer Science and lack of interest in studies. In Pakistan, mostly governments' school teachers showed strict attitude towards students. As evident from several studies indicated that the supportive and guidance attitude of teachers for their student (school going children) acts as a fundamental for student's healthy development (Hamre \& Pianta, 2001; Birch \& Ladd, 1998). Furthermore, some researches revealed that motivation of teachers for their students provided beneficial and helpful ways that increase the student's academic achievement (Midgley, Feldlaufer, \& Eccles, 1989).

The school history of the client also had been indicated that she had lack of interest in studies due to her academic performance issues and mother strict attitude. Sauer kate (2012) described in his research that one of the major contributing factor is healthy and satisfactory relationship of students with their teachers, parents and peer groups for the student's successful academic performance.

\section{Conclusion}

In the light of discussion, it is concluded that the proper use of the Cognitive Behavior Techniques as therapy provided more effective results for the reduction and improvement in Depressive Symptoms, Academic Difficulties and Low Self-esteem Problems in a mainstream school child. 


\section{Recommendation}

The study recommended that, the class teacher of the client to follow-up the intervention plan that used with her in order to support and boost her depressive symptoms, academic difficulties and low self-esteem problems.

\section{Implications}

The present case study was conducted on mainstream school child who is suffering in depressive symptoms, low self-esteem issues and some academic problems. The finding of this case study revealed that Cognitive Behavior Techniques as a therapy provided more beneficial results for the psychological treatment and management of a mainstream school child. The current case study was based on Pakistani culture and can also be used as reference for the future researches on mental health of mainstream school children.

\section{References}

Adam, I. L., \& Dudas, B. (2013). Cognitive Behavioral Therapy (CBT) of Depressive Disorders. Retrieved from: dol: 10.5772/54200.

Alesi, M., Rappo, G., Pepi, A. (2014) Depression, Anxiety at School and Self-Esteem in Children with Learning Disabilities. J Psychol Abnorm Child 3: 125. doi:10.4172/23299525.1000125.

American Psychiatric Association. (2013). Diagnostic and statistical manual of mental disorders: DSM-V. Washington, DC: Author.

Annie, W., Howard, W. S., Mildred, M. W. (1996). "Achievement and Ability Tests-Definition ofthe Domain",Educational Measurement2, UniversityPress of America, pp.2-5.

Arnberg, A., \& Öst, L. G. (2014). CBT for Children with Depressive Symptoms: A Meta Analysis. Journal of Cognitive Behavior Therapy. Vol. 43(4), pp. 1-14. doi:10.1080/16506073.2014.947316. Retrieved from: https://www.researchgate.net/publication/266085198

Birch, S. H., \& Ladd, G. (1998). Children's interpersonal behaviors and the teacher-child relationship. Journal of Developmental Psychology Vol. 34 (5). Pp. 934-946.

Davison, G. C. \& Neale, M. J., (2003). Book of Abnormal Psychology-800 pages.

Doodman, P., Zadeh, A. M., \& Changizi, B. A. (2017). Study of thce Relationship between SelfEsteem and Academic Achievement among High School Students in Lamerd City. Payam Noor University, Tehran, Iran, Department of Education and Psychology. International Journal of Scientific Study, Vol. 5. Retrieved from: doi: 10.17354/2017/032.

Edwards, S. D. (2005). A psychology of breathing methods. International Journal of Mental Health Promotion, 7(4), 28-34.

Ferkany, M. (2008). The educational importance of self-esteem. Journal of Philosophy of Education, Vol. 42 (1).

Furr, R. M., \& Funder, D. C. (2007). Behavioral observation. In R. W. Robins, R. C. Fraley, \& R. F. Krueger (Eds.), Handbook of research methods in personality psychology (p. 273291). The Guilford Press.

Grolnick, W. S., Friendly, R. W., \& Bellas, V. M. (2009). Parenting and children's motivation at school. In K. R. Wenzel \& A. Wigfield (Eds.), Educational psychology handbook series. Handbook of motivation at school (p. 279-300). 
Gottfried, A. W., \& Fleming, J. S. (2001). Continuity of Academic Intrinsic Motivation from Childhood Through Late Adolescence. Journal of Educational Psychology, 93(1), 3-13. Retrived from: doi: 10.1037/0022-0663.93.1.3.

Greenier, K. D., Kernis, M. H., \& Waschull, S. B. (1995). Not all high (or low) self-esteem people are the same: Theory and research on stability of self-esteem. In M. H. Kernis (Ed.), Plenum series in social/clinical psychology. Efficacy, agency, and self-esteem (p. 5171). Plenum Press.

Hamre, B. K., \& Pianta, R. C., (2001). Early Teacher-Child Relationships and the Trajectory of Children's School Outcomes through Eighth Grade. Journal of Child Development, Vol. 72, No. 2, pp. 625-638. Retrieved from: http://www.jstor.org/stable/1132418.

Hdid, B., \& Maliqi, A. (2015). The Correlation between Academic Success and Depressive Symptoms among Students in Kosovo. Retrieved from: doi: 10.4236/psych.2015.614173.

Hoyle, E. (1986). Policies of School Management, Suffllok. The press Itd.

Humphrey, N. (2004). The Death of the Feel-Good Factor? : Self-Esteem in the Educational Context. International journal of Social Psychology. Vol. 25 (3), 347-360.

Kovacs, M. (1979). "The Children's Depression Inventory." Psychopharmacology Bulletin, 21 (4), 995-998.

Laveena, N., Meena, M., Nelson, P. (2018). A Study on the Self Esteem and Academic Performance among the Students. International Journal of Health Sciences and Pharmacy Vol. 2(1). Available on: https://ssrn.com/abstract=3121006.

Mahmood, I., \& Sheikh, H. (1989). The Translation and Adaptation of WechslerMemory Scale. (From1) into Urdu and Development of Local Norms (Unpublished master's thesis). University of Punjab.

Midgley, C., Feldlaufer, H., \& Eccles, J. (1989). Change in Teacher Efficacy and Student Selfand Task-Related Beliefs in Mathematics during the Transition to Junior High School. Journal of EducationalPsychology,81, 247-258. Retrieved from: http://dx.doi.org/10.1037/0022-0663.81.2.247.

Miltenberger. (1997). General Principles and Empirically Supported Techniques of Cognitive Behavioral Techniques.

Miller, G. A. (1956). The magical number seven, plus or minus two: Some limits on our capacity for processing information. Psychological Review, 63(2), 81-97.

Mohamed, S. M. (2017) Effect of Cognitive Behavioral Treatment Program on Anxiety and Self-Esteem among Secondary School Students. American Journal of Nursing Science. Vol. 6 (3), pp. 193-201. doi: 10.11648/j.ajns.20170603.17.

Retrieved from: http://www.scienscepublishinggroup.com/j/ajns

Narad, A., \& Abdullah, B. (2016). Academic Performance of Senior Secondary School Students: Influence of Parental Encouragement and School Environment. Rupkatha Journal on Interdisciplinary Studies in Humanities. Vol.8(2). Retrieved from: doi: http://dx.doi.org/10.21659/rupkatha.v8n2.02

Pelish, D. P. (2006). Effects of a self-esteem intervention program on school-age children. Journal of Pediatric nursing. Vol. 32(4).

Retrieved From: https://www.researchgate.net/signup.SignUp.html?hdrsu=1

Riebe, G., Fan, M. Y., Unützer, J., \& Vannoy, S. (2012). Activity scheduling as a core component of effective care management for late-life depression. International journal of geriatric psychiatry, 27(12), 1298-1304. doi:10.1002/gps.3784. 
Rono, J. K., \& Reuben, L. C. (2015). Factors that affect students and popils' academic performance in Kericho West district: A case study of Seretut location. International Journal of Information Research and Review. Vol. 2, pp. 792-796. Retrieved from: http://www.ijirr.com

Rosenberg, M. (1965). Society and the adolescent self-image. Princeton, NJ: Princeton University Press.

Saleem, S., \& Mahmood, Z. (2010). The development of Self-esteem, Scale for schildren. Pakistan Journal of Psychological Research, 26 (1), 1-12.

Santrock, J. W. (2006). Educational Psychology (rd.ed). New York: McGraw-Hill. Sauer, Kate, "The Impact of Student Interest and Instructor Effectiveness on Student Performance" (2012). Education Masters.Paper 243.

Retrieved from: https://fisherpub.sjfc.edu/education_ETD_masters.

Sedikides, C., \& Gress, A. P. (2003). Portraits of the self. In M. A. Hogg \& J. Cooper (Eds.), Sage Handbook of social psychology (pp. 110-138). London, United Kingdom: Sage.

Slavin, R. 2006. Educational Psychology: Theory and Practice. Boston: Allyn and Bacon.

Verboom, C. E., Sijtsema, J. J., Verhulst, F. C., Brenda, W. J., \& Penninx, H. (2003). Longitudinal associations between depressive problems, academic performance, and social functioning in adolescent boys and girls. Department of Psychiatry, University Medical Center. International Journal of Psychology, Vol 2, pp. 220-331.

Zyromski, B., \& Joseph, A. E., (2008). Utilizing Cognitive Behavioral Interventions to Positively Impact Academic Achievement in Middle School Students. Journal of School Counseling. Vol.6 (15). Retrieved from: https://files.eric.ed.gov/fulltext/EJ894786.pdf 